\title{
Short-Term Efficacy and Safety of Switching from a Latanoprost/Timolol Fixed Combination to a Latanoprost/Carteolol Fixed Combination
}

This article was published in the following Dove Press journal: Clinical Ophthalmology

\author{
Kenji Inoue' \\ Hua Piao' \\ Mayumi Iwasa' \\ Kyoko Ishida $\mathbb{D}^{2}$ \\ Goji Tomita ${ }^{2}$ \\ 'Inouye Eye Hospital, Tokyo, Japan; \\ ${ }^{2}$ Department of Ophthalmology, Toho \\ University Ohashi Medical Center, Tokyo, \\ Japan
}

\begin{abstract}
Purpose: To investigate the short-term intraocular pressure-lowering efficacy and safety of switching from a fixed combination of latanoprost/timolol to a fixed combination of latanoprost/carteolol.
\end{abstract}

Patients and Methods: The subjects were 30 eyes of 30 adult patients with primary openangle glaucoma, normal-tension glaucoma, or ocular hypertension who were using a latanoprost-/timolol-fixed combination with insufficient intraocular pressure-lowering efficacy or adverse reactions. The subjects were switched from once-daily latanoprost/timolol to once-daily latanoprost/carteolol with no washout interval. Intraocular pressure, tear film break-up time, corneal epithelial defects, conjunctival hyperemia, blood pressure, and pulse rate were measured and compared before and 1 and 3 months after switching. Patients were monitored for adverse reactions at each visit, and dropouts were recorded.

Results: The mean intraocular pressure at 1 month $(15.9 \pm 3.1 \mathrm{mmHg})$ and 3 months $(16.3$ $\pm 3.8 \mathrm{mmHg}$ ) was not significantly different from that at baseline $(16.1 \pm 3.1 \mathrm{mmHg})$. The tear film break-up time and corneal epithelial defects were significantly improved after switching ( $p<0.01$ and $p<0.0001$, respectively). There was a significant decrease in systolic blood pressure after 1 month and diastolic pressure after 3 months $(\mathrm{p}<0.05)$. There was no significant change in pulse rate during the study. Adverse reactions (blurred vision, blepharitis, and conjunctival hyperemia) occurred in 3 patients $(10.0 \%)$. Four patients $(13.3 \%)$ discontinued treatment during the 3-month study period.

Conclusion: A switch from a fixed combination of latanoprost/timolol to that of latanoprost/ carteolol can maintain intraocular pressure and adherence with once-daily administration while improving tear film break-up time and corneal epithelial defects.

Keywords: adverse reactions, eye drops, glaucoma, intraocular pressure
Correspondence: Kenji Inoue Inouye Eye Hospital, Chiyoda-ku, Tokyo, Japan

Tel +8I 332950911

Fax +81332950917

Email inoue-k@inouye-eye.or.jp

\section{Introduction}

Eye drops containing a fixed combination of latanoprost/carteolol (LCFC) have been approved for use in Japan since January 2017. Eye drops containing a prostaglandin/ $\beta$-blocker fixed combination are normally used when switching from concomitant prostaglandin analog and $\beta$-blocker therapy, from monotherapy with a prostaglandin analog or $\beta$-blocker for additional efficacy, or from another prostaglandin/ $\beta$-blocker fixed combination. We have previously investigated the effects of a switch from latanoprost and carteolol therapy to an LCFC. ${ }^{1}$ In that study, there was no significant difference in intraocular pressure (IOP) after switching and adherence was improved because of a decrease in the number of daily doses 
required; furthermore, many patients preferred treatment with an LCFC. In a Phase III clinical trial conducted in Japan, IOP was lowered effectively and safely in patients who were switched from latanoprost or carteolol monotherapy to LCFC. $^{2}$ However, there has been no report on switching from another fixed prostaglandin/ $\beta$-blocker combination to LCFC. The aim of this study was to prospectively investigate the short-term IOP-lowering efficacy and safety and usability of LCFC in patients with primary open-angle glaucoma (POAG), normal-tension glaucoma (NTG), or ocular hypertension $(\mathrm{OH})$ after a switch from a fixed combination of latanoprost/timolol (LTFC).

\section{Patients and Methods}

Patients who attended the outpatient clinic at Inouye Eye Hospital from January 2017 to December 2018 were enrolled in the study. The study protocol was approved by the Inouye Eye Hospital ethics committee, adhered to the tenets of the Declaration of Helsinki, and was registered with the UMIN clinical trials registry (ID UMIN000026231). All patients provided written informed consent after receiving an explanation of the purpose and details of the study and before any study procedure or examination was performed.

\section{Subjects}

The subjects were patients with POAG, NTG, or OH who were older than 20 years of age, had used LTFC (Xalacom ${ }^{\circledR}$ combination eye drops, Pfizer Japan Inc., Tokyo, Japan) for more than 1 month, and were being considered for a switch to other medication because of insufficient IOP-lowering effects or an adverse reaction. Patients who used the same medications for more than 1 month at baseline were allowed to continue using Rho-associated protein kinase, $\alpha 1$-blockers, $\alpha 2$-agonists, and carbonic anhydrase inhibitors during the study. The diagnostic criteria used for POAG were as follows: (1) typical morphologic characteristics, such as thinning of the rim of the optic disc and defects in the retinal nerve fiber layer; (2) an abnormal visual field detected with high reliability and reproducibility and corresponding to the criteria outlined in (1); (3) exclusion of other eye diseases or congenital abnormalities that could cause an abnormal visual field; (4) a primary open angle on gonioscopy; and (5) IOP $>21 \mathrm{mmHg}$ on serial measurements, allowing for diurnal variation. The diagnostic criteria used for NTG were as follows: (1) typical morphologic characteristics, such as thinning of optic disc rim and defects in the retinal nerve fiber layer; (2) an abnormal visual field detected with high reliability and reproducibility and corresponding to the criteria outlined in (1); (3) exclusion of other eye diseases or congenital abnormalities that could cause an abnormal visual field; (4) a primary open angle on gonioscopy; and (5) IOP $\leq 21 \mathrm{mmHg}$ on serial measurements, allowing for diurnal variation. The diagnostic criteria used for $\mathrm{OH}$ were as follows: (1) IOP $>21 \mathrm{mmHg}$ on serial measurements, allowing for diurnal variation; (2) no thinning of the rim of the optic disc or defects in the retinal nerve fiber layer; (3) a normal visual field detected with high reliability and reproducibility and corresponding to criteria (1) and (2); and (4) a primary open angle on gonioscopy. The exclusion criteria were as follows: (1) anomalies of the cornea or corneal disease; (2) a history of keratorefractive surgery; (3) irritation or infection affecting the anterior eye or eyelid; (4) a history of glaucoma surgery (eg, laser trabeculoplasty, filtration surgery, or trabeculotomy); (5) a history of anterior or intraocular surgery within 3 months of enrollment in the study; (6) planned administration of an additional glaucoma medication or planned a prohibited concomitant therapy (eg, laser therapy or invasive surgery involving the eyes) or a concomitant use of a contraindicated drug (eg, IOP-lowering medication administered via the oral or intravenous route, adrenocorticosteroid therapy [unless applied topically to an area not around the eyes]); (7) a history of allergy to any of the study agents or reagents used in the study; (8) pregnancy, potential for pregnancy, or lactation; and (9) unsuitability for enrolment in the opinion of the attending physician.

\section{Medication}

The patients were switched from once-daily LTFC to once-daily LCFC (Mikeluna ${ }^{\circledR}$ combination ophthalmic solution; Otsuka Pharmaceutical Co Ltd., Tokushima, Japan) without a washout interval. The patients were instructed to instill the LCFC drops at the same time as the previous LTFC drops. The patients continued using any medications that had been used before the study.

\section{Methods}

IOP, conjunctival hyperemia, corneal epithelial defects (SPK), tear breakup time (BUT), blood pressure (BP), and pulse rate were evaluated or measured at baseline, and at 1 and 3 months after switching in all patients. Additionally, patients who were using only LTFC at baseline were observed as a subgroup. The visual field was examined 
using the Humphrey visual field test program (30-2 SITA Standard) before switching, and a questionnaire on the usability of the medications was completed 1 month after switching (Figure 1). Patients were investigated for adverse reactions at each visit and any dropouts were recorded.

\section{Efficacy Evaluation}

The primary endpoint of this study was IOP-lowering efficacy. IOP was measured with a Goldmann tonometer in each patient at baseline, and at 1 and 3 months after switching, at the same hour. IOP was measured twice at each time point and the mean value was used for analysis. The statistical analysis included one eye from each patient, ie, the eye with higher IOP at baseline if both eyes satisfied the inclusion criteria, the right eye if the IOP was elevated to the same extent in both eyes, or the only affected eye if it met the inclusion criteria.

\section{Safety Evaluation}

BP and pulse rate were measured using an automated BP monitor (UDEX super TYPE, Elquest Inc., Chiba, Japan) at baseline and at 1 and 3 months after switching. The results were compared before and after the switch. SPK, conjunctival hyperemia, BUT, adverse reactions, and patient withdrawals were investigated 3 months after switching. The National Eye Institute guidelines were used to evaluate $\mathrm{SPK}^{3}$ in five areas of the cornea, ie, central, superior, inferior, temporal, and nasal, on a 15-point scale. The SPK in each area was scored on a scale of $0-3$ as follows: 0 , none; 1 , 1-5 punctuate staining dots; $2,6-15$ punctuate staining dots; or $3,>16$ punctuate staining dots, a $\geq 1-\mathrm{mm}$ patch, or a corneal filament. Conjunctival hyperemia was evaluated in accordance with the guideline for clinical management of allergic conjunctival disease (second edition). ${ }^{4}$ Using the pictures in the guideline, a few vasodilations were graded as mild, many vasodilations as moderate, and continuous vasodilation as severe. The BUT was measured three times consecutively, and the mean value was used for the analysis.

\section{Usability Evaluation}

The questionnaire regarding ease of use of the eye drops was administered 1 month after switching (Figure 1).

\section{Statistical Analysis}

IOP, BP, pulse rate, BUT, and corneal epithelial defect scores at baseline and at 1 and 3 months after switching were investigated by analysis of variance and Bonferroni and Dunn analyses. The conjunctival hyperemia scores

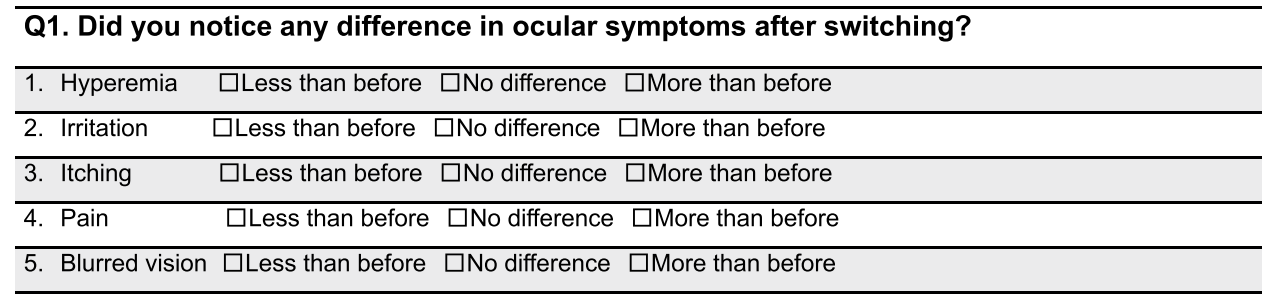

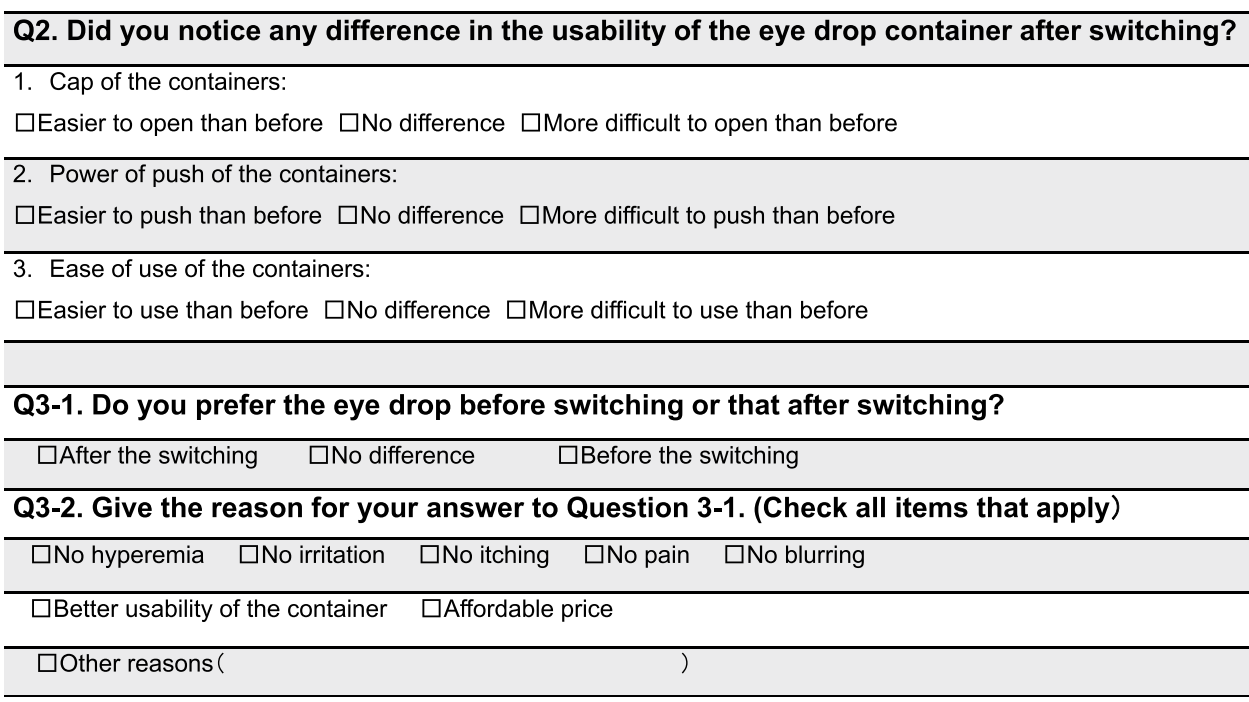

Figure I Questionnaire regarding preference of eye drops. 
were compared using the chi-squared test. A p-value $<0.05$ was considered statistically significant.

The change of intraocular pressure was predicted to be $0 \mathrm{~mm} \mathrm{Hg}$ after switching, the non-inferiority margin was set as $1.5 \mathrm{mmHg}$, standard deviation was $2.5 \mathrm{mmHg}$, and power was $80 \%$ (paired $t$-test with a $5 \%$ level of significance).

\section{Results \\ Subjects}

The subjects were 30 eyes of 30 patients ( 7 men, 23 women; mean age 71.3 \pm 10.3 [45-86] years; Table 1). The ophthalmic diagnoses were as follows: POAG in 20 patients, NTG in 9, and $\mathrm{OH}$ in 1 . The mean number of medications taken was $1.8 \pm 1.0$ (1-4); medications in use at baseline are shown in Table 1 . The duration of administration of LTFC was more than 6 months. Table 1 shows the medications prescribed to lower IOP. The mean MD value was $-6.70 \pm 6.86(-21.09,1.53) \mathrm{dB}$. Four patients instilled the LCFC drops in the morning

Table I Demographic and Clinical Characteristics of Patients

\begin{tabular}{|c|c|}
\hline Diagnosis & $\begin{array}{l}\text { POAG: } 20 \text { patients ( } 20 \text { eyes) } \\
\text { NTG: } 9 \text { patients ( } 9 \text { eyes) } \\
\text { OH: I patient ( } 1 \text { eye })\end{array}$ \\
\hline $\begin{array}{l}\text { Reason for switch of } \\
\text { medication }\end{array}$ & $\begin{array}{l}\text { Increased intraocular pressure: I patient } \\
\text { Adverse reactions: } 29 \text { patients } \\
\text {-SPK: } 27 \\
\text {-Irritation: I } \\
\text {-Conjunctival hyperemia: I }\end{array}$ \\
\hline Sex, male/female & $7 / 23$ \\
\hline Age, years & $71.3 \pm 10.3(45-86)$ \\
\hline $\mathrm{IOP}, \mathrm{mmHg}$ & $16.1 \pm 3.1(10-26)$ \\
\hline Deviation value, $d B$ & $-6.70 \pm 6.86(-21.09,1.53)$ \\
\hline Medications, $\mathrm{n}$ & $\begin{array}{l}\text { I.8 } 1.0(\mathrm{I}-4) \\
\text { Latanoprost/timolol fixed combination: } \\
\text { I7 patients } \\
\text { + Brimonidine: } 5 \text { patients } \\
\text { + Pilocarpine: I patient } \\
\text { + Brimonidine + brinzolamide: } 3 \\
\text { patients } \\
\text { + Brimonidine + bunazosin: I patient } \\
\text { + Brimonidine + brinzolamide + } \\
\text { ripasudil: } 3 \text { patients }\end{array}$ \\
\hline
\end{tabular}

Notes: The data are shown as the mean \pm standard deviation (range) or the number as appropriate.

Abbreviations: POAG, primary open-angle glaucoma; NTG, normal-tension glaucoma; $\mathrm{OH}$, ocular hypertension; SPK, Corneal epithelial defects; IOP, intraocular pressure. and 26 instilled them at night. The reason for switching medications was adverse reactions in 29 patients (SPK, $\mathrm{n}=27$; irritation, $\mathrm{n}=1$; conjunctival hyperemia, $\mathrm{n}=1$ ) and insufficient IOP-lowering efficacy in 1 patient. One patient discontinued the LCFC drops within 3 months of switching; therefore, IOP was measured in 30 patients at 1 month and in 29 at 3 months.

There were 17 patients in the LTFC subgroup, all of whom had been using only LTFC.

\section{Patient Preferences}

Thirty patients completed the questionnaire (Figure 2). Question 1 was "Did you notice any difference in ocular symptoms after switching?". The most common response was that ocular irritation was "less than before" $(n=14$, 46.7\%). Most patients answered "no difference" in conjunctival hyperemia, itching, pain, and blurred vision $(\mathrm{n}=21,70.0 \%$; $\mathrm{n}=19,63.3 \% ; \mathrm{n}=18,60.0 \% ; \mathrm{n}=17,56.7 \%$, respectively). Question 2 was "Did you notice any difference in the usability of the eye drop container after switching?" Most patients $(n=17,56.7 \%)$ answered that the container cap was "easier to open than before". There was no difference between the number of patients who answered that the container was "easier to use than before" and the number who answered "no difference" ( $n=14,46.7 \%)$. Question 3 was "Do you prefer the eye drop before switching or that after switching?". Ten patients $(33.3 \%)$ preferred the eye drop after switching, 17 (56.7\%) answered "no difference," and $3(10.0 \%)$ preferred the eye drop before switching. Patients who preferred the eye drop after switching did so because of "no irritation," "better usability of container," "no pain," "no hyperemia," "no itching," "no blurring," or another reason (no longer feeling tired, no need to apply a cold eye compress).

\section{Intraocular Pressure}

There was no significant difference in the mean IOP value after 1 month $(15.9 \pm 3.1 \mathrm{mmHg})$ and 3 months $(16.3 \pm 3.8$ $\mathrm{mmHg})$ when compared with the baseline value $(16.1 \pm 3.1$ mmHg; $p=0.70$; Figure 3 ) in all patients. The changes in IOP after switching were grouped on the basis of whether there was an increase of $\geq 2 \mathrm{mmHg}$, fluctuation within no more than $\pm 2 \mathrm{mmHg}$, and a decrease of $\geq 2 \mathrm{mmHg}$. Most patients had a reduction in IOP of less than $\pm 2 \mathrm{mmHg}$ after 1 and 3 months (Figure 4). In the LTFC subgroup, there was no difference in IOP after 1 and 3 months $(16.0 \pm 2.5 \mathrm{mmHg}$ and $16.1 \pm 2.2 \mathrm{mmHg}$, respectively) compared with the baseline value $(16.1 \pm 2.6 \mathrm{mmHg})$. The IOP in patients who changed to LCFC because of insufficient IOP-lowering efficacy 


\section{Question 1}

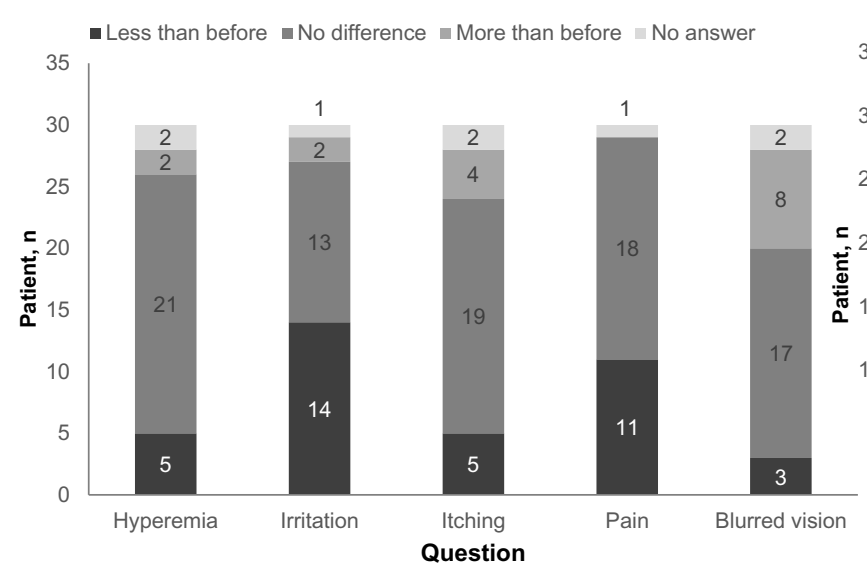

Question 2

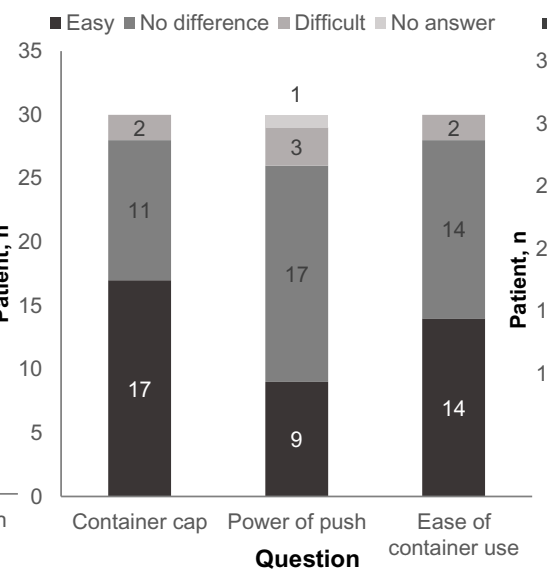

\section{Question 3}

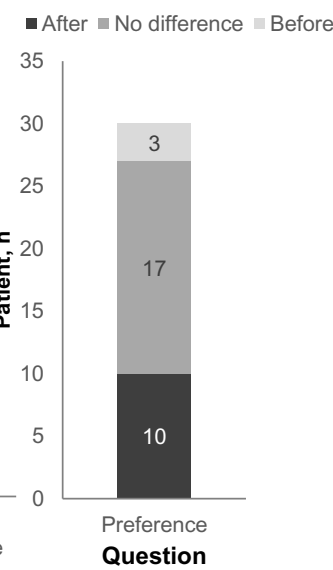

Figure 2 Patient preferences.

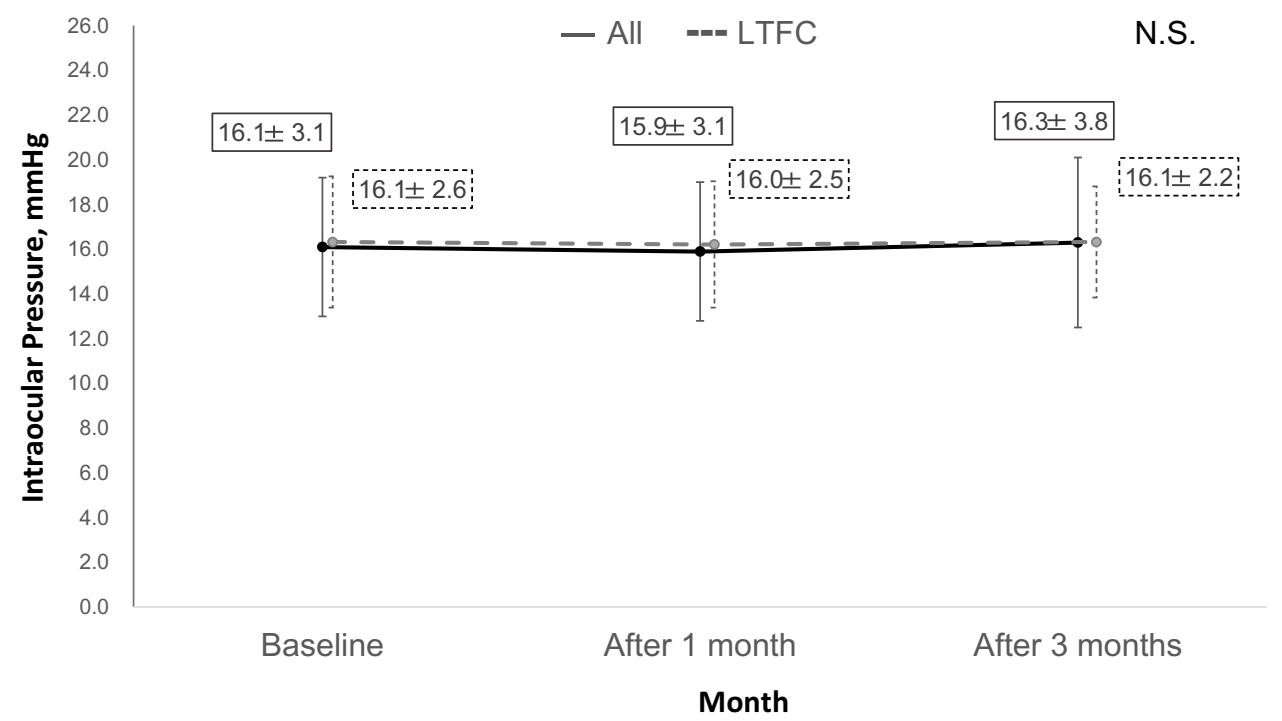

Figure 3 Intraocular pressure values before and after switching in all patients and the latanoprost/timolol fixed combination subgroup. Abbreviations: LTFC, latanoprost/timolol fixed combination; N.S., not statistically significant.

was decreased after 1 and 3 months $(16.0 \mathrm{mmHg}$ and 14.0 $\mathrm{mmHg}$, respectively) compared with the baseline value (18.0 $\mathrm{mmHg}$ ).

\section{Safety}

Compared with baseline, systolic BP significantly decreased after 1 month and diastolic BP significantly decreased after 3 months $(\mathrm{p}<0.05$; Table 2$)$. There was no difference in pulse rate at 1 and 3 months after switching $(\mathrm{p}=0.68)$. Conjunctival hyperemia observed in 2 patients at baseline disappeared after 1 month in 1 patient and was graded as mild in the other patient after 3 months.
Conjunctival hyperemia that was graded as mild at baseline in another patient was graded as moderate after 3 months. This patient discontinued the study. The average National Eye Institute scores in eyes with SPK were 1.0 \pm 1.1 after 1 month and $0.8 \pm 1.0$ after 3 months; both were significantly improved in comparison with the value of 2.9 \pm 2.1 at baseline $(\mathrm{p}<0.0001)$. BUT was significantly longer at 1 and 3 months $(8.8 \pm 2.2$ and $8.9 \pm 1.8$ seconds, respectively) than at baseline $(7.9 \pm 1.9$ seconds; $\mathrm{p}<0.01)$. Three patients $(10.0 \%)$ reported adverse reactions (blurred vision after 1 month, $\mathrm{n}=1$; blepharitis after 1 month, $\mathrm{n}=1$; conjunctival hyperemia after 3 months, $n=1$ ). Four patients 

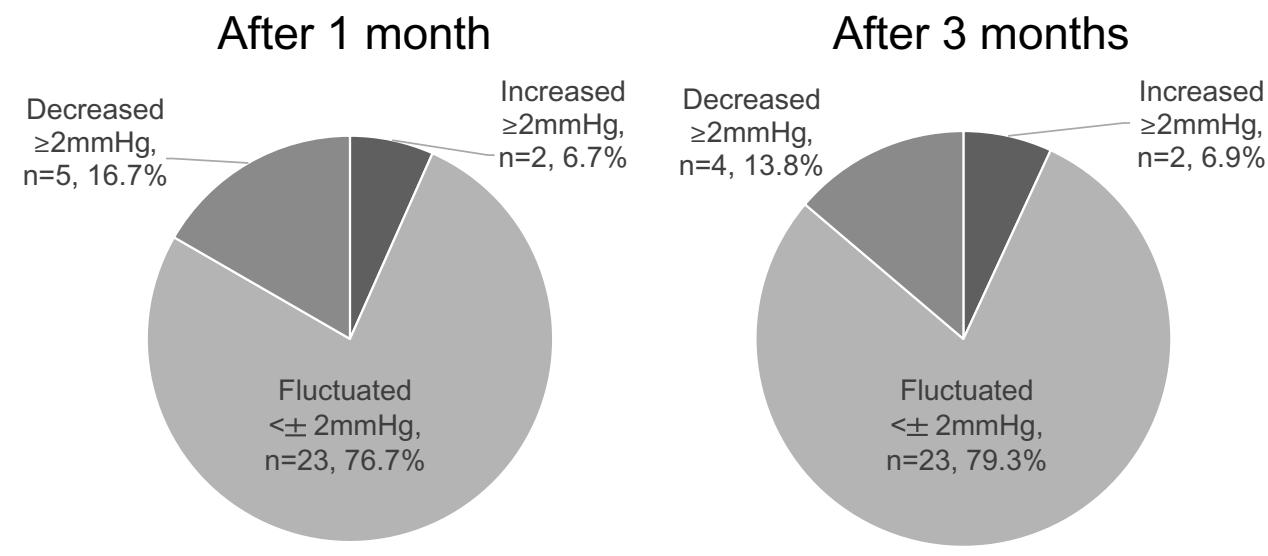

Figure 4 Intraocular pressure reduction at $\mathrm{I}$ and 3 months after switching.

(13.3\%) discontinued the study, including the two abovementioned patients with blepharitis after 1 month and conjunctival hyperemia after 3 months and 2 patients with an increase in IOP (from 14 to $16.5 \mathrm{mmHg}$ and from 19 to $30 \mathrm{mmHg}$ ) after 3 months. The patient with blepharitis had used only LTFC at baseline, and the patients with conjunctival hyperemia had used brimonidine, brinzolamide, and ripasudil with LTFC at baseline. The one patient with an increase in IOP (14 to 16.5 $\mathrm{mmHg}$ ) had used only LTFC; another patient (19 to 30 $\mathrm{mmHg}$ ) had used brimonidine and brinzolamide with LTFC. The patient who developed blepharitis on LCFC was switched back to LTFC, after which the blepharitis resolved. The conjunctival hyperemia in the other patient resolved after switching from brinzolamide and LCFC to tafluprost and a fixed combination of brinzolamide/timolol. The two patients with increased IOP switched back to LTFC, and their IOP decreased from 16.5 to $15.0 \mathrm{mmHg}$ and from 30.0 to $22.0 \mathrm{mmHg}$. The patient who changed to

Table 2 Systemic Blood Pressure and Pulse Rate Before and After Switching Medication

\begin{tabular}{|l|l|l|l|l|}
\hline & Baseline & $\begin{array}{l}\text { After I } \\
\text { month }\end{array}$ & $\begin{array}{l}\text { After 3 } \\
\text { months }\end{array}$ & P-value \\
\hline $\begin{array}{l}\text { Systemic BP } \\
(\mathrm{mmHg})\end{array}$ & & & & \\
- Systolic & $133.6 \pm 23.9$ & $123.8 \pm 18.8 *$ & $126.9 \pm 21.4$ & 0.0088 \\
- Diastolic & $73.5 \pm 13.8$ & $69.1 \pm 12.1$ & $67.6 \pm 11.8 *$ & 0.0271 \\
$\begin{array}{l}\text { Pulse rate } \\
\text { (beats/min) }\end{array}$ & $73.1 \pm 11.5$ & $73.3 \pm 9.4$ & $72.5 \pm 10.1$ & 0.6771 \\
\hline
\end{tabular}

Notes: The data are shown as the mean \pm standard deviation. ANOVA/Bonferroni and Dunn tests were used for the comparison. * $\mathrm{P}<0.05$.

Abbreviation: BP, blood pressure.
LCFC because of hyperemia discontinued using this product because the hyperemia had worsened at 1 and 3 months after switching. This patient recovered after changing from LCFC to a different medication. The adverse reaction in the patient who switched to LCFC because of irritation s resolved after the switch.

\section{Discussion}

In this study, we investigated the efficacy and safety of switching from LTFC to LCFC. There has been a crossover clinical trial in which patients on LTFC were switched to a fixed combination of travoprost/timolol that found IOP to be significantly lower on the fixed combination of travoprost/timolol than on LTFC. ${ }^{5}$ However, a meta-analysis found no significant difference in IOP-lowering efficacy between travoprost and latanoprost. ${ }^{6}$ Moreover, no significant difference in safety was found between these two medications. A further study in which patients were switched from LTFC to a fixed combination of tafluprost/timolol (TTFC) found no significant difference in IOP after the switch. ${ }^{7}$ This result was similar to that of the meta-analysis, which found no difference in IOP-lowering efficacy between latanoprost and tafluprost and a significant decrease in reports of eye irritation and eye pain after switching to TTFC. ${ }^{6}$ Another meta-analysis reported that the IOPlowering efficacy of a fixed combination of bimatoprost/timolol was better than that of LTFC and TTFC and that conjunctival hyperemia was less common with LTFC than with the fixed combination of bimatoprost/timolol. ${ }^{8}$

In the present study, there was no significant difference in the mean IOP reduction after the switch from LTFC to LCFC between the study population overall and the LTFC subgroup. Both preparations included latanoprost but the 
timolol in LTFC was changed to carteolol in LCFC. In the meta-analysis of studies in patients with glaucoma, there was no significant difference in the ability to achieve a reduction in IOP between timolol and carteolol. ${ }^{6}$ We obtained similar results in our study; however, during follow-up, we found an increase in IOP of more than 2 $\mathrm{mmHg}$ in $6.7 \%$ of patients at 1 month and $6.9 \%$ at 3 months (Figure 3). Therefore, careful follow-up is needed when switching patients from LTFC to LCFC.

We found that the National Eye Institute score for SPK improved significantly and that the BUT increased significantly after the switch from LTFC to LCFC. SPK causes deterioration of subjective symptoms such as foreign body sensation, decreased functional visual acuity, and lowered adherence. $^{9-11}$ Therefore, improving SPK is important. Differences in the excipients and/or antiseptic agents between timolol and carteolol could explain these improvements. Carteolol has intrinsic sympathomimetic activity and does not decrease corneal sensitivity to the same extent as timolol; therefore, it might also improve SPK and BUT. ${ }^{12}$ In a previous study of the effects of glaucoma medication, we found a significantly higher frequency of SPK in patients using timolol than in those using carteolol. ${ }^{13}$ The antiseptic component in LTFC is benzalkonium chloride and that in LCFC is edetate disodium and boric acid. The antiseptic effect of edetate disodium and boric acid has been reported to be weaker than that of benzalkonium chloride. ${ }^{14,15}$

In our study, systolic BP at 1 month and diastolic BP at 3 months decreased significantly after switching from LTFC to LCFC. There was a decrease in 10 patients and an increase in 2 patients in both systolic and diastolic BP at 1 and 3 months after switching; however, no patient discontinued LCFC because of BP-related signs or symptoms, indicating that the switch was not clinically problematic. There was no significant change in pulse rate after the switch. These findings are consistent with those of other studies that have compared the effects of timolol and carteolol on systolic and diastolic BP and pulse rate. ${ }^{16,17}$

Three patients in this study had conjunctival hyperemia at baseline that improved in 2 cases and worsened in 1 case after switching. Moreover, conjunctival hyperemia developed de novo in 1 patient after the switch. It may be that LCFC has a limited ability to penetrate the conjunctiva; however, we were not able to evaluate this possibility in such a small group of patients, and further studies in a larger sample are needed in the future.

Responses to the questionnaire indicated that there were no significant changes in the subjective symptoms of conjunctival hyperemia, itching, pain, or blurred vision after switching. Many patients reported lower levels of irritation after switching. LCFC was better than LTFC with regard to the ease of opening and using the container, and patients preferred LCFC after switching. The reasons given for preference of LCFC were lack of irritation and the container being more comfortable to use. The shape of the LCFC container is designed to fit in the hand and is difficult to roll. Ease of use and comfortable instillation are important for maintaining adherence.

This study has some limitations in that it was a single-arm switching study with a small sample size and evaluation of the efficacy of switching from LTFC to LCFC may have been affected by inclusion of patients who were using other medications. However, the possibility of adverse reactions or increased IOP in this study is expected to have been low, because, except for LTFC, the concomitant drugs did not change. Certain effects due to excessive medication (brimonidine, brinzolamide, and ripasudil) were noted only in one patient who discontinued the study because of conjunctival hyperemia. Our investigation of the efficacy and safety in the LTFC subgroup revealed no difference in IOP after switching. However, it has been reported that patients who show longterm drift on timolol may have a decrease in IOP when they switch from LTFC to LCFC containing carteolol. ${ }^{18}$ Conversely, it is possible that non-responders to carteolol may have an increase in IOP after switching to LCFC. However, 27 patients (90\%) in this study switched to LCFC because of the occurrence of SPK before switching. In these cases, the IOP-lowering efficacy was sufficient before switching; therefore, it was difficult to evaluate IOP. Finally, this was a short-term study and whether or not our findings are maintained in the long-term needs to be clarified.

\section{Conclusion}

In this prospective study, patients were followed up for 3 months after a switch from LTFC to LCFC. IOP and safety were maintained and SPK was improved after the switch. Adherence with treatment was maintained because patients still only needed to use one bottle of medication and instill the drops once daily after switching. A switch to LCFC was considered a good strategy in patients with glaucoma who had SPK despite using LTFC.

\section{Data Sharing Statement}

The participant data that support the findings of this study are available for five years after publication from the corresponding author, K.I., upon reasonable request. 


\section{Disclosure}

K. Inoue reports grants from Santen, Alcon, Senju, Allergan, Teijin, IQVIA Services JAPAN, Mayo, and Eli Lilly Japan; lecture fees from Santen, Otsuka, Senju, Kowa, Allergan, Novartis, and Wakamoto; consultant fees from Santen, Senju, and Kowa. K. Ishida reports lecture fees from Alcon, Pfizer, Santen, Senju, Otsuka, Kowa, AMO, Sucampo, GlaxoSmithKline, and Japan Ophthalmic Instruments Association; G. Tomita reports grants from Alcon, Eisai Pharmaceutical, Heidelberg GmBH, Pfizer, Santen, Senju, TOPCON, Handaya, Kowa, Otsuka, and AMO; lecture fees from Pfizer, Santen, Senju, Otsuka, and Japan Focus Company, consultant fee from Allergan Japan. The authors report no other conflicts of interest in this work.

\section{References}

1. Inoue K, Shiokawa M, Iwasa M, et al. Short-term efficacy and safety of a latanoprost/carteolol fixed combination switched from concomitant therapy to in patients with primary open-angle glaucoma or ocular hypertension. J Glaucoma. 2018;27:1175-1180. doi:10.1097/ IJG.0000000000001091

2. Yamamoto T, Ikegami T, Ishikawa Y, et al. Randomized, controlled, Phase 3 trials of carteolol/latanoprost fixes combination in primary open-angle glaucoma or ocular hypertension. Am J Ophthalmol. 2016;171:35-46. doi:10.1016/j.ajo.2016.08.022

3. Lemp MA. Report of the National Eye Institute/Industry Workshop on clinical trials in dry eyes. CLAO J. 1995;21:221-232.

4. Japanese Ocular Allergology Society. Guidelines for the clinical management of allergic conjunctival diseases. Nihon Ganka Gakkai Zasshi. 2010;114:833-870. [In Japanese].

5. Shoji T, Sato H, Mizukawa A, et al. Hypotensive effect of latanoprost/ timolol versus travoprost/timolol fixed combinations in NTG patients: a randomized, multicenter, crossover clinical trial. Invest Ophthalmol Vis Sci. 2013;54:6242-6247. doi:10.1167/iovs.13-11942

6. Li T, Lindsley K, Rouse B, et al. Comparative effectiveness of first-line medications for primary open-angle glaucoma: a systematic review and network meta-analysis. Ophthalmology. 2016;123:129-140. doi:10.1016/j. ophtha.2015.09.005
7. Suzuki K, Otsuka N, Hizaki H, et al; Tafluprost/Timolol Versus Latanoprost/Timolol (TTVLT) Study Group. Multicenter, randomized, controlled study comparing tafluprost/timolol fixed combination with latanoprost/timolol fixed combination in primary open-angle glaucoma and ocular hypertension. Adv Ther. 2018;35:796-808. doi:10.1007/s12325-018-0718-9

8. Aptel F, Cucherat M, Denis P. Efficacy and tolerability of prostaglandin-timolol fixed combinations: a meta-analysis of randomized clinical trials. Eur J Ophthalmol. 2012;22:5-18. doi:10.5301/ ejo. 5000009

9. Machida Y, Shoji J, Harada N, et al. Two patients with dry eye disease followed up using an expression assay of ocular surface mucin. Case Rep Ophthalmol. 2016;7:208-215. doi:10.1159/000445371

10. Kaido M, Ishida R, Dogru M, et al. The relation of functional visual acuity measurement methodology to tear functions and ocular surface status. Jpn J Ophthalmol. 2011;55:451-459. doi:10.1007/s10384-0110049-8

11. Kaštelan S, Tomić M, Soldo KM, et al. How ocular surface disease impacts the glaucoma treatment outcome. Biomed Res Int. 2013;696328.

12. Yabuochi Y, Kinoshita D. Cardiovascular studies of 5-(3-tertbutylamino-2-hydroxy) propoxy-3, 4-dihydrocarbostyril hydrochloride (OPC-1085), a new potent beta-adrenergic blocking agent. Jpn J Pharmacol. 1974;24:853-861. doi:10.1254/jjp.24.853

13. Inoue $\mathrm{K}$, Okugawa $\mathrm{K}$, Kato $\mathrm{S}$, et al. Ocular factors relevant to anti-glaucomatous eyedrop-related keratoepitheliopathy. J Glaucoma. 2003;12:480-485. doi:10.1097/00061198-200312000-00007

14. Burgalassi S, Chetoni P, Monti D, et al. Cytotoxicity of potential ocular permeation enhancers evaluated on rabbit and human corneal epithelial cell lines. Toxicol Lett. 2001;122:1-8. doi:10.1016/S03784274(01)00261-2

15. Uematsu M, Kumagami T, Shimoda K, et al. Polyoxyethylene hydrogenated castor oil modulates benzalkonium chloride toxicity: comparison of acute corneal barrier dysfunction induced by travoprost Z and travoprost. J Ocul Pharmacol Ther. 2011;27:437-444. doi:10.1089/jop.2010.0175

16. Stewart WC, Cohen S, Peter A, et al. Efficacy of carteolol hydrochloride $1 \%$ vs timolol maleate $0.5 \%$ in patients with increased intraocular pressure. Am J Ophthalmol. 1997;124:498-505. doi:10.1016/S00029394(14)70865-7

17. Scoville B, Mueller B, White BG, et al. A double-masked comparison of carteolol and timolol in ocular hypertension. Am J Ophthalmol. 1998;105:150-154. doi:10.1016/0002-9394(88)90178-X

18. Boger WP 3rd, Puliafito CA, Steinert RF, Langston DP. Long-term experience with timolol ophthalmic solution in patients with open-angle glaucoma. Ophthalmology. 1978;85:259-267. doi:10.1016/ S0161-6420(78)35673-6
Clinical Ophthalmology

\section{Publish your work in this journal}

Clinical Ophthalmology is an international, peer-reviewed journal covering all subspecialties within ophthalmology. Key topics include: Optometry; Visual science; Pharmacology and drug therapy in eye diseases; Basic Sciences; Primary and Secondary eye care; Patient Safety and Quality of Care Improvements. This journal is indexed on PubMed

\section{Dovepress}

Central and CAS, and is the official journal of The Society of Clinical Ophthalmology (SCO). The manuscript management system is completely online and includes a very quick and fair peer-review system, which is all easy to use. Visit http://www.dovepress.com/ testimonials.php to read real quotes from published authors. 